\title{
PENGARUH PEMBERIAN PENDIDIKAN KESEHATAN TENTANG HIPERTENSI KEHAMILAN TERHADAP UPAYA PEMELIHARAAN TEKANAN DARAH PADA IBU HAMIL DI DESA NGEBONG KECAMATAN DELANGGU KABUPATEN KLATEN
}

\author{
Oleh : \\ Rahayu Setyaningsih ${ }^{1}$ Endang Dwi Ningsih ${ }^{2}$ Megawati Ahmad ${ }^{3}$
}

\begin{abstract}
The Background of Pregnancy hipertension is the blood pressure increasing after 20 weeks of the gestation period $\geq 140 \mathrm{mmHg}$ for systolic and $\geq 90 \mathrm{mmHg}$ for diastolic.

Pregnancy hipertension can be occured whenever the pregnant women do not keep maintaining their blood pressure at the normal level. The background of this case is caused by the poor health knowledge of the women regarding the pregnancy hipertension.

The research aim to know the influence of the health education on the pregnant women to keep maintaining the blood pressure.

The subject were the 30 pregnant women in Ngebong village, Delanggu Distric, Klaten city.

The sampling technique is the saturated sampling (all the sample subject used).

The questionnaire methode before and after the education is given. The data analized by "t" test.

The result based on the dependent paired "t" test (uji t) with $\alpha=5 \%(0,05) ; P$ value got 0,000 it indicate : $P=0,000<\alpha=0,05$; it means the hypothesis acceptable.

The conclusion is having an influence of the health education of the blood hipertension on pregnancy given to make the effort on the pregnan women to keep maintaining their blood pressure in Ngebong village, Delanggu Distric, Klaten city.
\end{abstract}

Keywords : Health education, Pregnancy hipertension, Keep Maintaining blood pressure

\section{PENDAHULUAN}

Kehamilan adalah kondisi di mana seorang wanita memiliki janin yang sedang tumbuh di dalam tubuhnya. Kehamilan biasanya berkisar 40 minggu atau 9 bulan, dihitung dari awal periode menstruasi sampai melahirkan. Kehamilan merupakan suatu proses reproduksi yang perlu perawatan khusus, agar dapat berlangsung dengan baik kehamilan mengandung kehidupan ibu maupun janin. Resiko kehamilan ini bersifat dinamis, karena ibu hamil yang pada mulanya normal, secara tiba- tiba dapat menjadi beresiko tinggi. (Purwaningsih dan Fatmawati, 2010)

Gangguan kesehatan yang umum selama kehamilan adalah tekanan darah tinggi (hipertensi). Muncul dengan berbagai cara, insiden ini berkisar antara 5 hingga 10 persen. Hipertensi selama kehamilan tidak seperti hipertensi pada umumnya, tetapi mempunyai kaitan erat dengan angka kesakitan dan kematian yang tinggi baik pada janin maupun ibu. Komplikasi yang umum terjadi pada ibu adalah 
abrupsio plasenta, disseminated intravascular coagulation, perdarahan otak, gagal hati, dan gagal ginjal akut. Janin mempunyai resiko IUGR, prematur, dan kematian. (Varney, Kriebs, dan Gegor, 2006)

Gangguan hipertensi dalam kehamilan merupakan penyebab kedua tersering untuk kematian ibu di negara maju (setelah embolisme) dan mencangkup 15\% dari semua kematian ibu. (Norwitz dan Schorge, 2008)

Menurut Bobak, sebagaimana dikutip oleh Purwaningsih (2010), pengertian hipertensi adalah kenaikan nilai tekanan sistolik sebesar $30 \mathrm{mmHg}$ atau lebih atau kenaikan tekanan diastolik sebesar $15 \mathrm{mmHg}$ diatas nilai tekanan darah dasar ibu.

Indonesia belum memiliki data statistik vital yang langsung dapat menghitung Angka Kematian lbu (AKI). Estimasi AKI dalam Survei Demografi dan Kesehatan Indonesia (SDKI) diperoleh dengan mengumpulkan informasi dari saudara perempuan yang meninggal semasa kehamilan atau persalinan. AKI di Indonesia masih relatif lebih tinggi jika dibandingkan dengan negara-negara anggota ASEAN. Risiko kematian ibu karena melahirkan di Indonesia adalah 1 dari 65, dibandingkan dengan 1 dari 1.100 di Thailand. Penyebab kematian ibu adalah perdarahan, eklampsia atau gangguan akibat tekanan darah tinggi saat kehamilan, partus lama, komplikasi aborsi, dan infeksi. (UNDIP, 2004)

Untuk mengatasi penyebab diatas salah satunya dengan memberikan informasi kepada ibu hamil melalui pendidikan kesehatan .
Pendidikan kesehatan adalah segala upaya yang direncanakan untuk mempengaruhi orang lain baik individu, kelompok atau masyarakat sehingga mereka melakukan apa yang diharapkan oleh pelaku pendidikan. (Adnani, 2011)

Dari survei yang dilakukan di Desa Ngebong Kecamatan Delanggu Kabupaten Klaten pada bulan Oktober 2013 menunjukkan 4 dari 7 ibu hamil mengalami hipertensi, dengan tekanan sistolik berkisar $\geq$ $140 \mathrm{mmHg}$, dan tekanan diastolik berkisar $\geq 90 \mathrm{mmHg}$, dengan keluhan pusing juga bengkak di bagian kaki. Para ibu belum mengetahui penyebab hipertensi, terlebih bahaya hipertensi bagi kehamilannya. Hal ini karena minimnya penyuluhan kesehatan atau pendidikan kesehatan tentang bahaya hipertensi bagi kehamilan membuat para ibu kurang memberi perhatian khusus pada keadaan hipertensi yang dialami saat kehamilan, para ibu mengaku hanya memperoleh informasi tentang bahaya hipertensi kehamilan sesekali dari bidan saat memeriksakan kandungannya.

Tujuan umum penelitian ini adalah untuk mengetahui pengaruh pemberian pendidikan kesehatan tentang hipertensi kehamilan terhadap upaya pemeliharaan tekanan darah ibu hamil di Desa Ngebong Kecamatan Delanggu Kabupaten Klaten.

\section{METODE PENELITIAN}

Pada penelitian ini peneliti menggunakan rancangan penelitian pre experimental design dengan pendekatan metode one group pre test post test design. One group pre test-post test design adalah dilakukan pre test dahulu sebelum diberikan intervensi kemudian 
setelah diberikan intervensi lalu dilakukan post test. (Hidayat, 2003)

Pada penelitian ini, peneliti akan melakukan penelitian tentang pengaruh pendidikan kesehatan tentang hipertensi kehamilan terhadap upaya pemeliharaan tekanan darah ibu hamil di Desa Ngebong Kecamatan Delanggu Kabupaten Klaten. Peneliti memberikan perlakuan pendidikan kesehatan berupa penyuluhan dengan cara memberikan ceramah. Dalam penelitian ini yang menjadi sampel adalah ibu hamil di Desa Ngebong Kecamatan Delanggu Kabupaten Klaten sejumlah 30 orang.

Langkah-langkah dalam pengumpulan data yaitu dimulai dengan membagikan kuesioner. Selanjutnya peneliti melakukan penyuluhan atau pendidikan kesehatan tentang hipertensi kehamilan. Setelah selesai memberikan pendidikan kesehatan tentang hipertensi kehamilan, peneliti akan membagikan kuesioner kembali guna membandingkan upaya pemeliharaan tekanan darah ibu hamil setelah diberi pendidikan kesehatan tentang hipertensi kehamilan dan sebelum diberi pendidikan kesehatan tentang hipertensi kehamilan.

\section{HASIL PENELITIAN}

Pada penelitian yang dilakukan pada tanggal 20-23 Januari 2014 dengan jumlah responden sebanyak 30 orang maka diperoleh hasil penelitian sebagai berikut :
Tabel 1. Upaya memelihara tekanan darah pada ibu hamil sebelum diberi penkes

\begin{tabular}{|c|c|c|c|}
\hline No & $\begin{array}{c}\text { Upaya } \\
\text { memelihara } \\
\text { tekanan darah }\end{array}$ & $\mathrm{F}$ & $\%$ \\
\hline 1 & $6-10$ & 6 & $20 \%$ \\
\hline 2 & $11-15$ & 18 & $60 \%$ \\
\hline 3 & $16-20$ & 6 & $20 \%$ \\
\hline & Jumlah & 30 & $100 \%$ \\
\hline
\end{tabular}

Tabel 2. Analisa univariat

\begin{tabular}{|c|l|c|}
\hline No & Analisa univariat & Hasil \\
\hline 1 & Mean & 13.30 \\
\hline 2 & Median & 13.00 \\
\hline 3 & Modus & 13 \\
\hline
\end{tabular}

Tabel 3. Upaya memelihara tekanan darah pada ibu hamil setelah diberi penkes

\begin{tabular}{|c|c|c|c|}
\hline No & $\begin{array}{c}\text { Upaya } \\
\text { memelihara } \\
\text { tekanan } \\
\text { darah }\end{array}$ & $\mathrm{F}$ & $\%$ \\
\hline 1 & $6-10$ & 0 & $0 \%$ \\
\hline 2 & $11-15$ & 5 & $16,67 \%$ \\
\hline 3 & $16-20$ & 25 & $83,33 \%$ \\
\hline & Jumlah & 30 & $100 \%$ \\
\hline
\end{tabular}

Tabel 4. Analisa univariat

\begin{tabular}{|l|l|l|}
\hline No & Analisa univariat & Hasil \\
\hline 1 & Mean & 18.27 \\
\hline 2 & Median & 19.00 \\
\hline 3 & Modus & 20 \\
\hline
\end{tabular}

Berdasarkan hasil uji dengan menggunakan Dependent paired $t$ Test ( uji t) dengan $\alpha=5 \%(0.05)$ diperoleh $p$ sebesar 0.000 sehingga $p<0.05$, artinya hipotesa diterima maka diperoleh kesimpulan bahwa ada pengaruh pemberian pendidikan kesehatan tentang hipertensi kehamilan terhadap upaya pemeliharaan tekanan darah ibu hamil di Desa Ngebong Kecamatan Delanggu Kabupaten Klaten. 


\section{PEMBAHASAN}

1. Hasil perbandingan data frekuensi upaya memeliharaan tekanan darah pada ibu hamil di Desa Ngebong Kecamatan Delanggu Kabupaten Klaten.

Dari data tabel di atas dapat disimpulkan bahwa ada peningkatan baik jumlah responden pada rentang nilai yang lebih baik, nilai rata-rata, nilai tengah, nilai yang sering muncul pada upaya memelihara tekanan darah pada ibu hamil dari sebelum diberi pendidikan kesehatan dan setelah diberi pendidikan kesehatan.

Para responden mengatakan selama ini kurang memahami gejala dari hipertensi kehamilan sehingga mereka tidak tahu sedang mengalami hipertensi kehamilan yang membutuhkan perawatan khusus. Menurut Varney, Kriebs, dan Gegor (2006), Hipertensi kehamilan adalah peningkatan tekanan darah setelah 20 minggu kehamilan $\geq 140 \mathrm{mmHg}$ untuk sistolik dan $\geq 90 \mathrm{mmHg}$ untuk diastolik atau hasil evaluasi laboratorium yang abnormal selama kehamilan dan yang kembali normal 12 minggu pasca partum. Kurangnya pengetahuan para responden tentang hipertensi kehamilan seperti yang dijelaskan diatas membuat mereka kurang melakukan pencegahan untuk menghindari terjadinya hipertensi kehamilan. Untuk mengetahui ini diperlukan pemeriksaan tekanan darah yang rutin, dan segera tanggap terhadap gejala hipertensi kehamilan seperti yang dipaparkan oleh Purwaningsih dan Fatmawati (2011), diantaranya seperti peningkatan tekanan darah, pusing, edema, dan peningkatan berat badan yang abnormal . Maka dapat ditarik kesimpulan memelihara tekanan darah pada tekanan yang normal sangat diperlukan untuk menghindari hipertensi kehamilan pada ibu hamil.

2. Pengaruh pemberian pendidikan kesehatan tentang hipertensi kehamilan terhadap upaya pemeliharaan tekanan darah pada ibu hamil di Desa Ngebong Kecamatan Delanggu Kabupaten Klaten.

Dari hasil penelitian pengaruh pemberian pendidikan kesehatan tentang hipertensi kehamilan terhadap upaya pemeliharaan tekanan darah ibu hamil di Desa Ngebong Kecamatan Delanggu Kabupaten Klaten, diperoleh hasil uji dengan Dependent paired $\mathrm{t}$ Test (uji $\mathrm{t}$ ) dengan $\alpha=$ $5 \%$ (0.05) diperoleh $p$ sebesar 0.000 sehingga $p<0.05$, yang berarti Hipotesa diterima sehingga dapat ditarik kesimpulan bahwa ada pengaruh pemberian pendidikan kesehatan tentang hipertensi kehamilan terhadap upaya pemeliharaan tekanan darah ibu hamil di Desa Ngebong Kecamatan Delanggu Kabupaten Klaten. Hal tersebut sesuai yang diungkapkan oleh Nyswander (1947) dan dikutip oleh Fitriani (2011), pendidikan kesehatan adalah proses perubahan perilaku yang dinamis, bukan proses pemindahan materi (pesan) dari seseorang ke orang lain dan bukan pula seperangkat prosedur. Dari pengertian pendidikan kesehatan sendiri dapat diketahui bahwa proses dari pendidikan kesehatan akan menimbulkan perubahan perilaku dari seseorang yang 
tidak bisa menjadi bisa dari tidak ada upaya menjadi ada upaya. Sebelum terjadinya perubahan perilaku tentunya didahului dengan sikap yang sesuai .

Menurut Adnani (2011), sikap merupakan reaksi atau respons seseorang yang masih tertutup terhadap suatu stimulus atau objek. Manifestasi dari sikap tidak dapat langsung dilihat tetapi hanya ditafsirkan terlebih dahulu dari perilaku yang tertutup. Dalam kehidupan sehari-hari pengertian sikap adalah reaksi yang bersifat emosional terhadap stimulus sosial. Perubahan sikap sendiri bisa dilihat secara nyata dari perilaku namun juga tidak dapat dilihat secara langsung dalam arti masih pada tahap tertutup dimana di fase ini seseorang memiliki pengetahuan yang hendak dilakukan, barulah setelah didapati perubahan sikap maka terjadilah perubahan dari tidak ada upaya menjadi ada upaya untuk memelihara tekanan darah pada ibu hamil yaitu responden sendiri. Upaya itu sendiri adalah sikap para ibu hamil untuk memelihara tekanan darah guna menghindari atau meminimalisasikan kejadian hipertensi kehamilan yang lebih parah lagi adalah dengan rutin memeriksakan kesehatan ibu dan janin, utamanya pengukuran tekanan darah ibu guna mengidentifikasi hipertensi lebih dini, juga pengawasan terhadap kehidupan dan pertumbuhan janin dengan USG.

lbu hamil diharapkan memperhatikan benar pola diet makanan yang sehat dan seimbang, konsumsi garam berlebih, menghindari konsumsi bahan makanan atau minuman berkafein, menghindari untuk merokok terlebih minumminuman beralkohol, ibu hamil memerlukan waktu istirahat yang cukup dan pembatasan aktifitas fisik yang berat. Apabila sudah terjadi hipertensi pada kehamilan seorang ibu memerlukan monitoring ketat dari bidan atau dokter kandungan guna pengkolaborasian pemberian anti hipertensi.

Sehingga dapat disimpulkan bahwa pendidikan kesehatan mampu mempengaruhi upaya pemeliharaan tekanan darah pada ibu hamil di Desa Ngebong Kecamatan Delanggu Kabupaten Klaten. Jadi pendidikan kesehatan yang berfungsi memberikan pengetahuan yang baru ternyata juga mampu merubah sikap para ibu hamil untuk memelihara kehamilan mereka terlebih memelihara tekanan darah mereka.

\section{KESIMPULAN}

Terjadi peningkatan nilai upaya pemeliharaan sebelum diberi pendidikan dan setelah diberi pendidikan kesehatan, dan berdasarkan Dependent paired $\mathrm{t}$ Test ( uji t) dengan $\alpha=5 \%$ (0.05), diperoleh $p$ sebesar 0.000 sehingga $p<0.05$, yang berarti hipotesa diterima maka diperoleh kesimpulan bahwa ada pengaruh pemberian pendidikan kesehatan tentang hipertensi kehamilan terhadap upaya pemeliharaan tekanan darah ibu hamil di Desa Ngebong Kecamatan Delanggu Kabupaten Klaten.

\section{SARAN}

1. Bagi Ibu Hamil

Diharapkan memperluas pengetahuan mereka tentang 
upaya memelihara tekanan darah untuk menghindari terjadinya hipertensi pada masa kehamilannya

2. Bagi Tenaga Kesehatan Desa Diharapkan lebih meningkatkan penyuluhan dalam upaya pembinaan kesehatan ibu hamil yang lebih baik.

3. Bagi Masyarakat

Diharapkan lebih giat mengikuti pendidikan kesehatan agar memperoleh tambahan informasi kesehatan yang selama ini belum mampu diperoleh secara mandiri.

4. Bagi Peneliti Selanjutnya

Diharapkan dapat digunakan sebagai dasar untuk penelitian selanjutnya yang berkaitan dengan pengaruh pendidikan kesehatan tentang hipertensi kehamilan terhadap upaya pemeliharaan tekanan darah pada ibu hamil di Desa Ngebong Kecamatan Delanggu Kabupaten Klaten

\section{DAFTAR PUSTAKA}

Adnani, Hariza. Ilmu Kesehatan Masyarakat. Yogyakarta :NuhaMedika, 2011

Benson, Ralph C dan Martin L. Pernoll.Buku Saku Obstetri dan Ginekologi. Edisi IX. Alih bahasa Susiani Wijaya. Jakarta: EGC, 2008.

Fitriani, Sinta. Promosi Kesehatan. Yogyakarta : Graha Ilmu, 2011.
Fajar, Ibnu, et al. Statistika untuk Praktisi Kesehatan.

Yogyakarta: Graha IImu, 2009.

Hidayat, A. Aziz Alimul. Metode Penelitian Keperawatan dan Teknik Analisa.Data. Jakarta: Salemba Medika, 2003.

. Riset Keperawatan dan Teknik Penulisan IImiah. Jakarta: Salemba Medika, 2008.

Norwitz, Errol $\mathrm{R}$ dan John O. Schorge.Obstetri dan Ginekologi.Edisi II. Alih bahasa Diba Artsiyanti E. P. Jakarta: Erlangga, 2008.

Purwaningsih, Wahyu dan Siti Fatmawati. Asuhan KeperawatanMaternitas. Yogyakarta: NuhaMedika, 2010.

Rahayuningsih, Sri Utami. Psikologi Umum. Yogyakarta: Universitas Gajah Mada, 2008.

Riwidikdo, Handoko. Statistik untuk Penelitian Kesehatan. Yogyakarta: Pustaka Rihama, 2009.

Suyanto. Metodologi dan Aplikasi Penelitian keperawatan. Yogjakarta: NuhaMedika, 2011.

Varney, Helen, Jan M. Kriebs dan Carolyn L. Gegor. Buku Ajar Asuhan Kebidanan. Edisi IV. Alih bahasa Ana Lusiyana, et. al. Jakarta: EGC, 2006.

1 Dosen AKPER Panti Kosala Surakarta

2 Dosen AKPER Panti Kosala Surakarta

3 Mahasiswa AKPER Panti Kosala Surakarta 